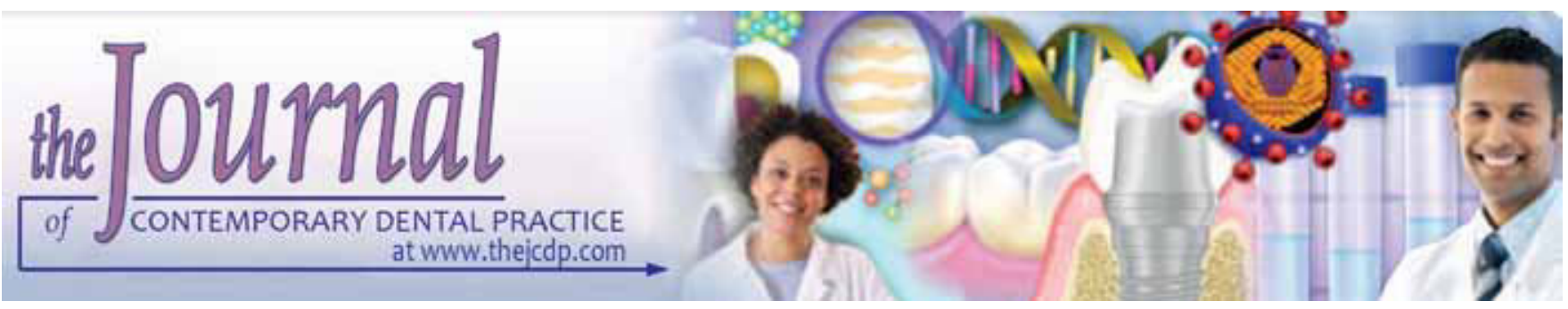

\title{
An Evaluation of Inter- and Intraobserver Reliability of Cone- beam Computed Tomography- and Two Dimensional-based Interpretations of Maxillary Canine Impactions using a Panel of Orthodontically Trained Observers
}

${ }^{1}$ Hala K Al-Homsi, ${ }^{2}$ Mohammad Y Hajeer

\begin{abstract}
Objectives: To assess intra- and interobserver agreement when evaluating maxillary impacted canines using cone beam computed tomography (CBCT) and two-dimensional (2D) images through a panel of orthodontically trained observers.

Materials and methods: An adult skull with permanent dentition was employed to perform 15 simulated maxillary canine impactions. Two sets of $2 \mathrm{D}$ and three-dimensional (3D) radiographic images were acquired. A panel of assessors including $11 \mathrm{PhD}$ and MSc postgraduate orthodontic students evaluated maxillary impacted canines using a standard questionnaire with 11 categorical variables. Kappa (K) statistics as well as Krippendorff's alpha $(\alpha)$ coefficients were used for the analysis of reliability.

Results: A high level of intraobserver agreement was found for both the CBCT- and 2D-based interpretations. The 11 observers demonstrated a higher interobserver agreement for the CBCTbased interpretations than that of the 2D-based interpretations ( $\alpha=0.68$ and 0.38 respectively). The employed 3D classifications canines was found to be reliable among observers on CBCT images for the labiopalatal position ( $K=0.87$ ), mesiodistal position, vertical position, labiopalatal inclination and mesiodistal inclination ( $\alpha=0.95,0.83,0.84$ and 0.92 respectively). The 2D-based interpretations were not in agreement among the 11 observers, except for the mesiodistal position $(\alpha=0.88)$ and mesiodistal inclination $(\alpha=0.88)$.
\end{abstract}

Conclusion: The intraobserver agreement was high for both the 2D- and the CBCT-based interpretations. The interobserver agreement for the CBCT-based interpretations was remarkably higher than that of the 2D-based interpretations. The utilized CBCT-based 3D classifications for the location and inclination

1,2Department of Orthodontics, University of Damascus, Dental School, Damascus, Syria

Corresponding Author: Mohammad Y Hajeer, Associate Professor, Department of Orthodontics, University of Damascus Dental School, Damascus, Syria, Phone: 00963113141343 e-mail: myhajeer@gmail.com of maxillary impacted canines were found reliable among observers.

Keywords: Interobserver reliability, Intraobserver reliability, Labiopalatal inclination, Labiopalatal position, Mesiodistal inclination, Mesiodistal position, Proximity, Resorption, Treatment plan, Vertical position.

How to cite this article: Al-Homsi HK, Hajeer MY. An Evaluation of Inter- and Intraobserver Reliability of Cone-beam Computed Tomography- and Two Dimensional-based Interpretations of Maxillary Canine Impactions using a Panel of Orthodontically Trained Observers. J Contemp Dent Pract 2015;16(8):648-656.

Source of support: Nil

Conflict of interest: None

\section{INTRODUCTION}

Maxillary canine impaction is one of the most challenging orthodontic problems that compromises esthetics and functions if not treated properly. ${ }^{1,2}$ The surgical and orthodontic management is difficult and time-consuming. ${ }^{3}$ The accurate localization of impacted maxillary canines is essential, especially if surgical intervention is required. ${ }^{3}$ Traditional radiographs two-dimensional (2D) have been employed for a long-time for the three-dimensional (3D) localization of the maxillary impacted canines. ${ }^{4}$ Still, 2D radiographs demonstrate inherent drawbacks resulting from overlapping, blurring, magnification and distortion. ${ }^{5,6}$ With the advent of cone beam computed tomography (CBCT), many authors have suggested the routine use of this technology in the diagnosis of maxillary or mandibular impacted canines, as well as the spatial relationships with the neighboring structures. The CBCTbased research work on maxillary impacted canines has made use of linear and angular measurements performed with dedicated software. ${ }^{2,7}$ In addition, vision-based 3D 
classifications of the spatial localization of the maxillary impacted canines and their relationships to the adjacent teeth have been suggested. ${ }^{2,8-10}$ Diagnostic indices have also been introduced based on some of the CBCT-based classifications. ${ }^{11,12}$ Adequate information about the reliability of observers in reading and interpreting CBCT data while evaluating canine impaction is still lacking in the literature.

There are only three published papers on the topic of within-observer or between-observer reliability when evaluating maxillary impacted canines using CBCT images. ${ }^{13-15}$ However, the study of Haney et al was restricted to the intraobserver reliability whereas that of Alqerban et al was limited to the interobserver reliability of three variables: labiopalatal position, proximity of the impacted canine to the adjacent teeth, and root resorption. ${ }^{13,14}$ Dalessandri et al evaluated the reliability of the components of the KPG classification which was recently introduced. This maxillary-canine-impaction index is based on the assessment of canine tip and root tip in three dimensions using the available three views of CBCT images in the aim of grading 'case difficulty' and 'treatment efficacy'. ${ }^{15}$ However, it seems that there is no published data comparing intra- and interobserver reliability when diagnosing and interpreting maxillary impacted canines using 2D and 3D images based on subjective classifications of different aspects of this problem.

Therefore, the objective was to evaluate the intraand interobserver reliability of CBCT and 2D-based assessments of the 3D localization of maxillary impacted canines as well as other related diagnostic aspects using a panel of orthodontically trained observers.

\section{MATERIALS AND METHODS}

The overall research project aimed to answer two questions: (1) about the diagnostic accuracy of employing CBCT images in the diagnosis of maxillary impacted canines compared to 2D images with reference to a 'gold standard' group (i.e. actual readings of simulated canine impactions on a dry skull), (2) about the intra- and interobserver reliability when using both imaging modalities. The first question is answered elsewhere, whereas the second question is answered in the current paper. ${ }^{16}$ This project was conducted at the department of orthodontics, University of Damascus dental school, Syria (between April 2014 and January 2015.

\section{Simulation of Maxillary Canine Impaction on a Dry Skull}

In this study, an adult dry skull with permanent dentition was used. This skull was obtained from the Department of Forensic Medicine, Faculty of Medicine of Damascus University (Syria).
A dentoalveolar osteotomy was carried out involving the right section teeth of the dentition (Figs 1 and 2). Then, the trabecular bone was removed by a diamond disk. The bone was grinded using ace bone mill ${ }^{\circledR}$ (ACE surgical Supply Co., Inc, Brockton, MA, USA) into small particles (Fig. 2), and was then mixed with a silicon orthodontic wax (OrthoSil ${ }^{\circledR}$, Dentsply Glenroe, Bradenton, FL, USA) to get a moldable compound, to hold bone and teeth together during the building of the different 15 impaction simulation. The simulation was done by adding the teeth back to the dental arch one by one using the compound of the silicone wax and the ground trabecular bone to hold teeth in place, and get the radiopaque property of the bone (Fig. 3).

The different simulated positions have been summarized in Table 1 . The distribution of canine positions in space was derived from a previous study on maxillary impacted canines on a Syrian sample. ${ }^{17}$ The employed classifications were derived from the literature, and on some occasions modified by the authors as explained in Table 1 and Figures 4 and 5. ${ }^{17-26}$ Three extramaxillary

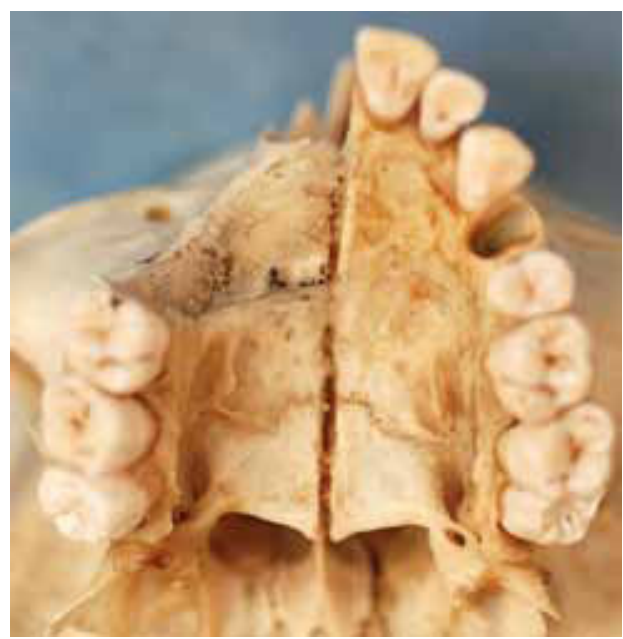

Fig. 1: The dentoalveolar osteotomy

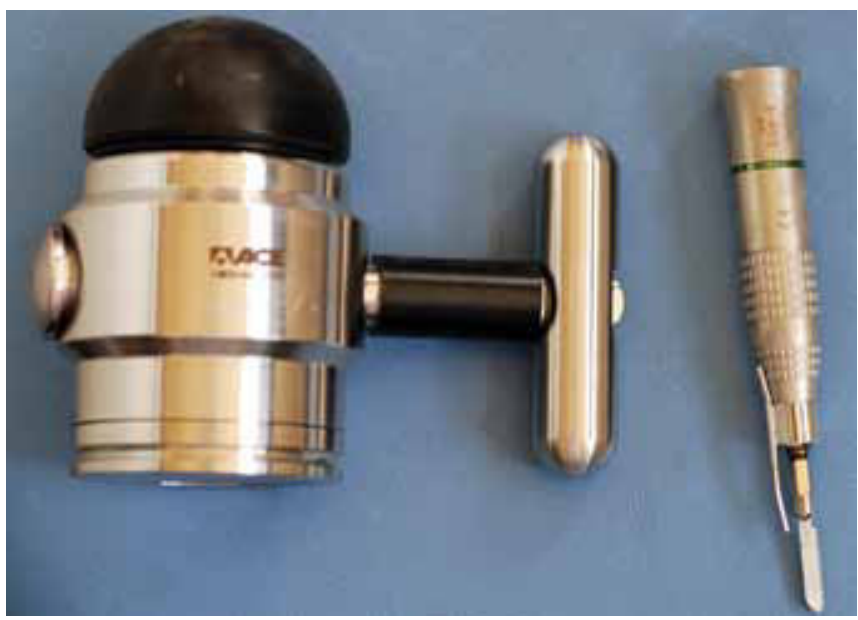

Fig. 2: The grinding tool (to the left) and the laboratory handpiece (to the right) 
Table 1: Details of the simulations of canine impactions performed on a dry skull $(n=15)$

\begin{tabular}{|c|c|c|c|c|c|c|c|}
\hline Case & $\begin{array}{l}\text { Labiopalatal } \\
\text { position* }^{*}\end{array}$ & $\begin{array}{l}\text { Mesiodistal } \\
\text { position }^{\dagger}\end{array}$ & $\begin{array}{l}\text { Vertical } \\
\text { position }^{\ddagger}\end{array}$ & $\begin{array}{l}\text { Labiopalatal } \\
\text { inclination }^{\S}\end{array}$ & $\begin{array}{l}\text { Mesiodistal } \\
\text { inclination }\end{array}$ & Proximity & Resorption \\
\hline 1 & Palatal to [1] & Section (5) & Apical third & $>45^{\circ}$ labially & $<45^{\circ}$ mesially & In contact with [1] and [2] & Resorption on 1 \\
\hline 2 & Palatal to [2] & Section (4) & Apical third & $<45^{\circ}$ labially & $<45^{\circ}$ distally & In contact with [1] and [2] & No resorption \\
\hline 3 & Palatal to [1] & Section (6) & Cervical third & $<45^{\circ}$ labially & $>45^{\circ}$ mesially & In contact with [1] and [2] & Resorption in [2] \\
\hline 4 & Palatal to the [2] & Section (4) & Middle third & $>45^{\circ}$ labially & $>45^{\circ}$ mesially & In contact with [2] & Resorption in [2] \\
\hline 5 & Palatal to the [2] & Section (2) & Cervical third & $>45^{\circ}$ labially & $<45^{\circ}$ distally & In contact with [2] & No resorption \\
\hline 6 & Palatal to the [1] & Section (6) & Middle third & $>45^{\circ}$ labially & $>45^{\circ}$ mesially & In contact with [1] & No resorption \\
\hline 7 & Palatal to the [1] & Section (5) & Cervical third & Perpendicular & $\begin{array}{l}\text { Parallel to the } \\
\text { mid-sagittal } \\
\text { Plane }\end{array}$ & No contact & No resorption \\
\hline 8 & Palatal to [1] & Section (5) & Cervical third & $<45^{\circ}$ labially & $<45^{\circ}$ distally & No contact & Resorption in [1] \\
\hline 9 & Palatal to [2] & Section (2) & Cervical third & $>45^{\circ}$ labially & $<45^{\circ}$ mesially & In contact with [2] & Resorption in [2] \\
\hline 10 & Palatal to [2] & Section (2) & Cervical third & $<45^{\circ}$ palatally & $<45^{\circ}$ distally & In contact with [2] & No resorption \\
\hline 11 & Labial to [1] & Section (6) & Apical third & $>45^{\circ}$ labially & $>45^{\circ}$ mesially & In contact with [1] & Resorption in [1] \\
\hline 12 & Labial to the [2] & Section (4) & Suprapical & $>45^{\circ}$ labially & $>45^{\circ}$ mesially & No contact & No resorption \\
\hline 13 & Labial to the [4] & Section (1) & Middle third & $>45^{\circ}$ palatally & $>45^{\circ}$ distally & No contact & No resorption \\
\hline 14 & In situ & Section (2) & Apical third & $<45^{\circ}$ labially & $<45^{\circ}$ mesially & Contact with [2] & Resorption in [2] \\
\hline 15 & In situ & Section (2) & Cervical third & $<45^{\circ}$ labially & $\begin{array}{l}\text { Parallel to the } \\
\text { central line }\end{array}$ & In contact with [2] & No resorption \\
\hline
\end{tabular}

[1] Central incisor; [2] Lateral incisor; [4] First premolar; *The Labiopalatal position is classified into three categories including labial, in situ and palatal impaction. ${ }^{8,19}{ }^{\dagger}$ The mesiodistal position is classified into six-category classification which is a modification of the five

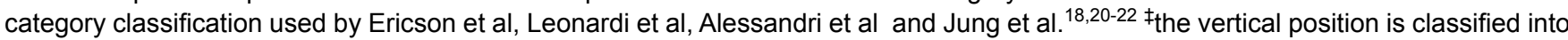
four category classification which is a modification of the five category classification by merging the coronal and the cervical thirds of the adjacent tooth. ${ }^{17,19,23}$ sthe labiopalatal inclinations were set according to a five-category classification in which the $45^{\circ}$ represented the cut-

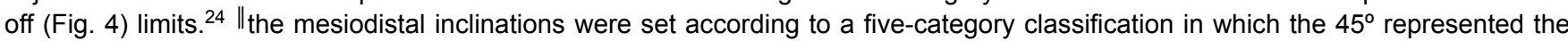
cut-off limits (Figs $5 \mathrm{~A}$ and B). ${ }^{25,26}$

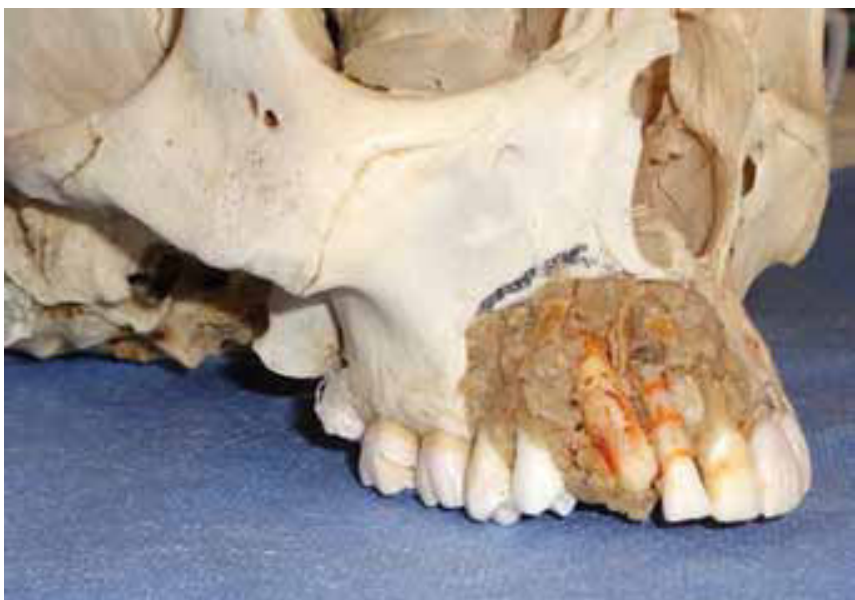

Fig. 3: Impaction case setup using the compound of the silicone wax and the ground trabecular bone

central incisors and four lateral incisors with intact roots, cementum and enamel were obtained to perform resorption on the roots of these teeth.

\section{Radiographic Imaging}

The 2D images package of the skull consisted of: (1) a panoramic radiograph acquired by Soredex ${ }^{\circledR}$ (Soredex, Tuusula, Finland) using exposure parameters of $15 \mathrm{sec}-$ onds $/ 44 \mathrm{kV} / 15 \mathrm{~mA}$, (2) a lateral cephalogram acquired

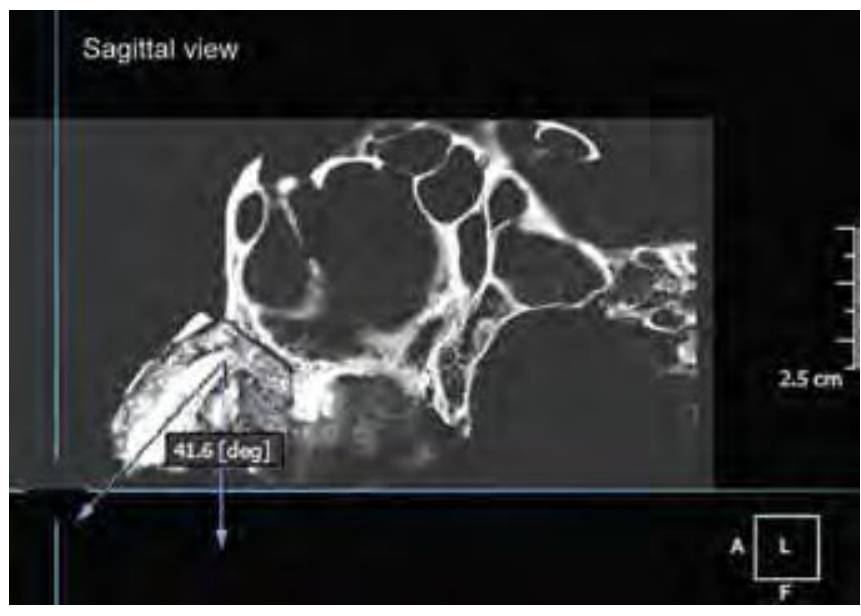

Fig. 4: The labiopalatal inclination of the impacted canine: the angle between the long axis of the impacted canine and a line perpendicular to horizontal plane when evaluated from a sagittal view. A $45^{\circ}$ threshold was set in the labial and palatal inclinations to differentiate between highly and slightly inclined canines

by Soredex ${ }^{\circledR}$ (Soredex, Tuusula, Finland), and (3) a pair of periapical images with different projections utilizing the horizontal parallax technique. ${ }^{27}$ A standardized position of the scanned skull was maintained by performing all the exposures by the same technical operator, and by securing the scanned skull to the panoramic bipod and cephalometric ear rods with the assistance of 
An Evaluation of Inter- and Intraobserver Reliability of Cone-beam Computed Tomography

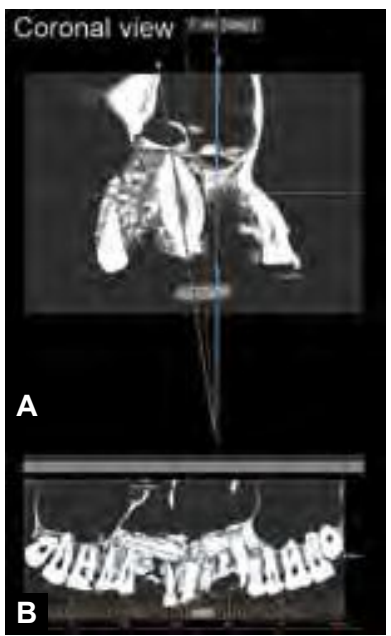

Figs $\mathbf{5 A}$ and $\mathbf{B}$ : $(\mathrm{A})$ The mesiodistal inclination of the impacted canines: the angle between the long axis of the impacted canine and the mid-sagittal plane when evaluated from a coronal view and (B) mesiodistal inclination when evaluated CBCT-derived panoramic view. $A 45^{\circ}$ threshold was set in the mesial and distal inclinations to differentiate between highly and slightly inclined canines

a wooden rod extending through the foramen magnum. This was used to ensure the parallelism of the Frankfort horizontal plane (from porion to orbitale) to the floor. The accurate orientation of the skull was adjusted according to the $3 \mathrm{D}$ intersecting planes of the red beam. This wooden rod was used to eliminate any radiopaque artifacts that would have occurred if a metallic one had been used.

The 3D image was captured by Picasso ${ }^{\circledR}$ Pro CBCT system (Vatech ${ }^{\mathrm{TM}}$, Seoul, South Korea), which was used with a voxel size of $0.2 \mathrm{~mm}$, field view of $70 \times 120 \mathrm{~mm}$, tube voltage of $70 \mathrm{kV}$, tube current of $15 \mathrm{~mA}$ with grey scale of 16 bit per pixel and a scanning time of 40 seconds. A standardized position of the scanned skull was maintained by the accurate orientation of the skull according to the 3D intersecting planes of the red beam. The CBCT image was performed with the skull immersed under water in plastic transparent box in an attempt to mimic the performance of the soft-tissue in attenuating and scattering radiation and eliminating artifacts to obtain images of appropriate contrast. ${ }^{28}$

\section{Case Presentation and Panel Assessment}

The 2D and 3D sets were assigned codes and reviewed in a random order to be evaluated by a panel of assessors that consisted of 11 postgraduate orthodontic students (three $\mathrm{PhD}$ students who had completed their MSc specialty training, six at the end of their MSc orthodontic program and two at the beginning of this program) (Table 2).

The $2 \mathrm{D}$ radiographs were displayed as hardcopies while the 3D images were reviewed using EzImplantCD viewer-Dental 3D software (Version 1.5.8265.1), to allow 3D model manipulation. Each assessor was allowed
Table 2: 'Baseline observers' panel characteristics

\begin{tabular}{ll}
\hline $\begin{array}{l}\text { Number of observers } \\
\text { Educational level }\end{array}$ & $\begin{array}{l}\text { 11 observers } \\
2 \text { observers were at the beginning of } \\
\text { their MSc orthodontic program } \\
6 \text { observers were at the end of their MSc } \\
\text { orthodontic program } \\
3 \text { observers were PhD students } \\
5 \text { females } \\
6 \text { males } \\
\text { Gender }\end{array}$ \\
CBCT diagnostic & $\begin{array}{l}\text { They received training on CBCT in the } \\
\text { department of orthodontics, } \\
\text { skills }\end{array}$ \\
\hline
\end{tabular}

to view the model in 3D as well as any desired view (i.e. coronally, sagittally or axially). All the tools were allowed including: zooming in, zooming out, translation and rotation.

The assessment process was held in two sessions (the $2 \mathrm{D}$ radiographic set assessment session, followed by the CBCT assessment session) at an interval of 3 weeks. Both 2D and 3D sessions were considered as ' $\mathrm{T} 1{ }^{\prime}$ assessment. The assessors were asked to complete a questionnaire at each session, which required the diagnosis of the following aspects: (1) canine position (labiopalatally, mesiodistally, and vertically), (2) canine inclination (labiopalatally, mesiodistally), (3) proximity to adjacent teeth, (4) presence or absence of impacted-canine-induced resorption, (5) possible treatment plan, and (6) expected treatment difficulty.

A calibration session was held before the main assessment sessions took place. This session lasted for 30 to 45 minutes, and the observers were instructed on how to diagnose an impacted canine using the $2 \mathrm{D}$ and $\mathrm{CBCT}$ records utilizing the employed categorizations. They were given the definitions of the 3D categorizations of spatial positioning and inclination as well as those of canine contact and resorption. Examples were viewed and illustrated to ensure consistent understanding among assessors (Figs 4 and 5). In order to evaluate intraobserver reliability, each participating observer was asked to revaluate eight randomly selected cases in a separate session 1 month later, and this was considered 'T2' assessment.

\section{DATA ANALYSIS}

The intraobserver agreement was assessed by Kappa statistics for the nominal and dichotomous variables. A kappa value between 0 and 0.20 indicates a slight level of agreement, 0.21 and 0.40 a fair level of agreement, 0.41 and 0.60 a moderate level of agreement, 0.61 and $0.80 \mathrm{a}$ substantial agreement, and, 0.81 and 1 as almost perfect agreement. ${ }^{29}$ The intraobserver agreement was assessed by means of Krippendorff's alpha coefficient for the ordinal 
variables. The significance of differences between the first assessment (T1) and the second assessment (T2) was assessed by McNemar, McNemar-Bowker or Wilcoxon signed-rank tests for the dichotomous, nominal and ordinal variables respectively.

The interobserver agreement was assessed by means of Krippendorff's alpha coefficient and the agreement was considered reliable when $\alpha \geq 0.800$, tentative when 0.800 $>\alpha \geq 0.667$, and discarded when $\alpha<0.667$. . $^{30}$

\section{RESULTS}

The CBCT-based assessments between T1 and T2 demonstrated a high level of intraobserver agreement ( $\alpha=0.87-1$; Table 3). The 2D-based assessments between T1 and T2 demonstrated a high level of intraobserver agreement ( $\alpha=0.83-1$; Table 4 ). No significant differences were observed between $\mathrm{T} 1$ and $\mathrm{T} 2$ for all of the CBCT- and 2D-based assessments (Tables 5 and 6).

The observers' responses based on CBCT were superiorly in agreement as compared to those based on 2D imaging, with an average of a moderate interobserver agreement for the former $(\alpha=0.68)$ and a low interobserver agreement on average for the later $(\alpha=0.38$; Table 7).

With regard to interobserver consistency, CBCT-based assessments showed a high agreement in terms of the 3D localization and inclination for labiopalatal position $(\mathrm{K}=0.87)$, mesiodistal and vertical positions as well as labiopalatal and mesiodistal inclinations $(\alpha=0.87,0.95$, $0.83,0.84$ and 0.92 respectively; Table 7 ). The CBCT-based assessments demonstrated a low level of interobserver agreement in terms of the proximity assessment, canineimpaction-induced resorption, expected treatment plan
$(\mathrm{K}=0.58,0.38$ and 0.12 respectively; Table 7$)$, and the estimated case difficulty ( $\alpha=0.24$; Table 7).

The observers' assessments were not in consensus, depending on $2 \mathrm{D}$ radiographic data with respect to the majority of the variables, except for the mesiodistal position $(\alpha=0.88)$ and mesiodistal inclination $(\alpha=0.88$; Table 7).

\section{DISCUSSION}

It seems that this is the first study to evaluate the reliability of using CBCT imaging in the 3D localization of maxillary impacted canines, as well as in the assessment of their relationships with the adjacent teeth as compared to the traditional 2D methods, by a panel of orthodontically trained observers.

The findings of the current study demonstrated a high level of intraobserver consistency in the diagnosis of maxillary impacted canines irrespective of the utilized radiographic modality. This may be explained by the clear perspective and the strict definitions every observer had in his mind after the calibration session.

This finding was inconsistent with that documented by Haney et al who found low level of intrarater agreement, particularly when assessing the labiopalatal, mesiodistal and vertical positions $(\mathrm{K}=0.77,0.61$ and 0.53 , respectively for CBCT-based interpretations; compared to $\mathrm{K}=0.87,0.92$ and 0.73 , respectively for 2D-based interpretations). Haney et al drew a conclusion that the intraobserver reliability of the 2D-based assessments was superior to that of the CBCT-based assessments. ${ }^{13}$ This may be explained by their employment of seven still 2D images of the maxillary dentition obtained from the CBCT rendered model, instead of allowing for 3D manipulation

Table 3: Kappa and Krippendorf's alpha coefficients for intrarater agreement between T1 and T2 in terms of CBCT-based assessments

\begin{tabular}{lllllllllllll}
\hline Variable & Obs 1 & Obs 2 & Obs 3 & Obs 4 & Obs 5 & Obs 6 & Obs 7 & Obs 8 & Obs 9 & Obs 10 & Obs 11 Mean \\
\hline $\mathrm{LPP}^{*}$ & 1 & 0.6 & 1 & 1 & 1 & 1 & 1 & 1 & 1 & 1 & 1 & 0.96 \\
$\mathrm{MDP}^{\dagger}$ & 1 & 1 & 1 & 1 & 1 & 0.91 & 1 & 1 & 1 & 1 & 0.91 & 0.98 \\
$\mathrm{VP}^{\dagger}$ & 1 & 0.9 & 1 & 1 & 1 & 1 & 1 & 1 & 1 & 1 & 0.54 & 0.95 \\
$\mathrm{LPI}^{\dagger}$ & 1 & 1 & 1 & 1 & 1 & 1 & 1 & 1 & 1 & 0.91 & 1 & 0.99 \\
$\mathrm{MDI}^{\dagger}$ & 0.75 & 1 & 1 & 1 & 1 & 1 & 1 & 1 & 1 & 0.98 & 1 & 0.98 \\
$\mathrm{C}^{*}$ & 1 & 1 & 1 & 0.4 & 1 & 1 & 1 & 1 & 1 & 1 & 1 & 0.95 \\
$\mathrm{Cl}^{*}$ & 0.56 & 1 & 1 & 0.5 & 1 & 1 & 1 & 1 & 1 & 1 & 1 & 0.91 \\
$\mathrm{R}^{*}$ & 1 & 1 & 1 & 1 & 1 & 1 & 1 & 1 & 1 & 1 & 1 & 0.95 \\
$\mathrm{RI}^{*}$ & 0.6 & 1 & 1 & 1 & 1 & 1 & 1 & 1 & 1 & 1 & 1 & 0.96 \\
Treat $^{*}$ & 1 & 1 & 1 & 1 & 1 & 1 & 1 & 1 & 1 & 1 & 1 & 1 \\
Diff & 0.79 & 0.53 & 1 & 1 & 1 & 1 & 1 & 1 & 1 & 1 & 0.96 & 0.93 \\
Mean & 0.88 & 0.87 & 1 & 0.9 & 1 & 0.99 & 1 & 1 & 1 & 0.99 & 0.95 & 0.96 \\
\hline
\end{tabular}

LPP: Labiopalatal position; MDP: Mesiodistal position; VP: Vertical position; LPI: Labiopalatal inclination; MDI: Mesiodistal inclination; C: Contact; Cl: Contacted incisor; R: Resorption; RI: Resorbed incisor; Treat: Treatment plan; Diff: Difficulty of the case; Obs: Observer; *Employing Kappa coefficient: $0-0.20$ as slight, $0.21-0.40$ as fair, $0.41-0.60$ as moderate, $0.61-0.80$ as substantial, and $0.81-1$ as almost perfect agreement. ${ }^{29}$; ${ }^{\mathrm{E}}$ Employing Krippendorff's alpha coefficient: $\alpha \geq 0.800$ (high), $0.800>\alpha \geq 0.667$ (tentative), $\alpha<0.667$ (low) ${ }^{30}$ 
An Evaluation of Inter- and Intraobserver Reliability of Cone-beam Computed Tomography

Table 4: Kappa and Krippendorf's alpha coefficients for intrarater agreement between T1 and T2 in terms of 2D-based assessments

\begin{tabular}{|c|c|c|c|c|c|c|c|c|c|c|c|c|}
\hline Variable & Obs 1 & Obs 2 & Obs 3 & Obs 4 & Obs 5 & Obs 6 & Obs 7 & Obs 8 & Obs 9 & Obs 10 & Obs 11 & Mean \\
\hline $\mathrm{LPP}^{*}$ & 1 & 1 & 1 & 1 & 1 & 0.6 & 1 & 0.56 & 1 & 1 & 0.5 & 0.83 \\
\hline $\mathrm{MDP}^{\dagger}$ & 1 & 1 & 1 & 1 & 0.79 & 0.91 & 1 & 1 & 1 & 1 & 1 & 0.97 \\
\hline $\mathrm{VP}^{\dagger}$ & 0.91 & 1 & 1 & 1 & 0.53 & 1 & 1 & 1 & 1 & 1 & 1 & 0.95 \\
\hline $\mathrm{LPI}^{\dagger}$ & 1 & 0.9 & 1 & 1 & 1 & 1 & 1 & 1 & 1 & 0.83 & 1 & 0.98 \\
\hline $\mathrm{MDI}^{\dagger}$ & 1 & 1 & 1 & 1 & 0.9 & 0.53 & 1 & 1 & 1 & 1 & 1 & 0.95 \\
\hline$C^{*}$ & 1 & 1 & 1 & 1 & 1 & 1 & 1 & 1 & 1 & 1 & 0.5 & 0.95 \\
\hline $\mathrm{Cl}^{*}$ & 1 & 1 & 1 & 1 & 1 & 1 & 1 & 1 & 1 & 1 & 0.56 & 0.96 \\
\hline$R^{*}$ & 1 & 1 & 1 & 1 & 1 & 1 & 1 & 1 & 1 & 1 & 1 & 1 \\
\hline $\mathrm{RI}^{*}$ & 1 & 1 & 1 & 1 & 1 & 1 & 1 & 1 & 1 & 1 & 1 & 1 \\
\hline Treat* & 1 & 1 & 1 & 1 & 1 & 1 & 1 & 1 & 1 & 1 & 0.6 & 0.96 \\
\hline Diff $^{\dagger}$ & 0.38 & 0.79 & 0.9 & 1 & 0.16 & 0.54 & 0.83 & 1 & 0.91 & 1 & 1 & 0.77 \\
\hline Mean & 0.94 & 0.97 & 0.99 & 1 & 0.85 & 0.87 & 0.98 & 0.96 & 0.99 & 0.98 & 0.83 & 0.94 \\
\hline
\end{tabular}

LPP: Labiopalatal position; MDP: Mesiodistal position; VP: Vertical position; LPI: Labiopalatal inclination; MDI: Mesiodistal inclination; C: Contact; Cl: Contacted incisor; R: Resorption; RI: Resorbed incisor; Treat: Treatment plan; Diff: Difficulty of the case; Obs: Observer; *Employing Kappa coefficient: $0-0.20$ as slight, $0.21-0.40$ as fair, $0.41-0.60$ as moderate, $0.61-0.80$ as substantial, and $0.81-1$ as almost perfect agreement. ${ }^{29}$; ${ }^{\dagger}$ Employing Krippendorff's alpha coefficient: $\alpha \geq 0.800$ high, $0.800>\alpha \geq 0.667$ tentative, $\alpha<0.667$ low $^{30}$

Table 5: Significance of differences between T1 and T2 in terms of CBCT-based assessments

\begin{tabular}{llllllllllll}
\hline Variable & Obs 1 & Obs 2 & Obs 3 & Obs 4 & Obs 5 & Obs 6 & Obs 7 & Obs 8 & Obs 9 & Obs 10 & Obs 11 \\
\hline $\mathrm{LPP}^{*}$ & - & - & - & 1 & - & 1 & - & - & - & - & - \\
$\mathrm{MDP}^{\dagger}$ & 1 & 1 & 1 & 1 & 1 & 0.32 & 1 & 1 & 1 & 1 & 0.32 \\
$\mathrm{VP}^{\dagger}$ & 1 & 0.32 & 1 & 1 & 1 & 1 & 1 & 1 & 1 & 1 & 0.66 \\
$\mathrm{LPI}^{\dagger}$ & 1 & 1 & 1 & 1 & 1 & 1 & 1 & 1 & 1 & 0.32 & 1 \\
$\mathrm{MDI}^{\dagger}$ & 0.32 & 1 & 1 & 1 & 1 & 1 & 1 & 1 & 1 & 1 & 1 \\
$\mathrm{C}^{\ddagger}$ & 1 & 1 & 1 & 1 & 1 & - & - & - & 1 & 1 & 1 \\
$\mathrm{Cl}^{*}$ & 0.32 & 1 & 1 & 0.32 & 1 & 1 & 1 & 1 & 1 & 1 & 1 \\
$\mathrm{R}^{\ddagger}$ & 1 & 1 & 1 & 1 & 1 & 1 & 1 & - & 1 & 1 & 1 \\
$\mathrm{RI}^{*}$ & 0.32 & 1 & 1 & 1 & 1 & 0.32 & 1 & 1 & 1 & 1 & 1 \\
Treat* & 1 & 1 & 1 & 1 & 1 & 1 & 1 & 1 & 1 & 1 & 1 \\
Diff & 0.32 & 0.32 & 1 & 1 & 1 & 1 & 1 & 1 & 1 & 1 & 1 \\
\hline
\end{tabular}

LPP: Labiopalatal position; MDP: Mesiodistal position; VP: Vertical position; LPI: Labiopalatal inclination; MDI: Mesiodistal inclination; C: Contact; Cl: Contacted incisor; R: Resorption; RI: Resorbed incisor; Treat: Treatment plan; Diff: Difficulty of the case; Obs: Observer;

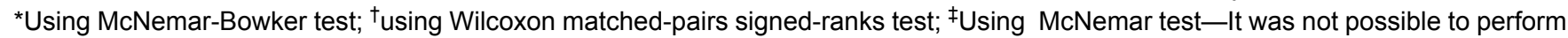
the McNemar-Bowker for some nominal variables and McNemar for some dichotomous variables because the observer's responses were consistent between T1 and T2; therefore, the statistical software considered these variables 'constant' and no result was give

by their observers. Another reason may be related to the fact that their assessors were a mixture of orthodontists and oral surgeons who might have been more familiar with the use of $2 \mathrm{D}$ images rather than $\mathrm{CBCT}$ images in the diagnosis of such abnormalities.

The high intraobserver agreement when assessing the labiopalatal position on CBCT ( $\mathrm{K}=0.96$ on an average) was in consistent with the results reported by Hering who employed a two-category labiopalatal classification, Haney et al who employed a three-category labiopalatal classification, and Dalessandri et al who employed a fivelevel categorization for the allocation of canine crown tip in space. ${ }^{13,15,31}$ Furthermore, the high intraobserver reliability found in the current study regarding the vertical assessment goes in line with findings of Dalessandri et al when they used the KPG index on their CBCT images. ${ }^{15}$

The 2D-based assessment of the labiopalatal categorization showed a high level of intraobserver agreement
$(\mathrm{K}=0.83$ on an average). This finding was in concordance with the high intrarater reliability found by Hering, Fox et al and Armstrong et al who employed a two-category labiopalatal classification; and Haney et al who employed a three-category labiopalatal classification. ${ }^{13,31-33}$

The overall interrater reliability of the CBCT-based assessments was superior to that of the 2D-based assessments (Krippendorff's alpha coefficients of 0.68 and 0.38 on an average respectively).

The high agreement of the CBCT-based assessments among the observers involved the overall 3D localization of the impacted canines (i.e. labiopalatal, mesiodistal, vertical positions, and labiopalatal and mesiodistal inclinations). It should be noted that the assessment was performed by a panel of orthodontically trained observers who received their clinical training in the same department, which may have played a role in ensuring homogeneity in their views and opinions. The age ranged 
Table 6: Significance of differences between T1 and T2 in terms of 2D-based assessments

\begin{tabular}{|c|c|c|c|c|c|c|c|c|c|c|c|}
\hline Variable & Obs 1 & Obs 2 & Obs 3 & Obs 4 & Obs 5 & Obs 6 & Obs 7 & Obs 8 & Obs 9 & Obs 10 & Obs 11 \\
\hline LPP $^{*}$ & 1 & 1 & 1 & 1 & 1 & - & 1 & - & 1 & 1 & 1 \\
\hline $\mathrm{MDP}^{\dagger}$ & 1 & 1 & 1 & 1 & 0.32 & 1 & 1 & 1 & 1 & 0.32 & 1 \\
\hline $\mathrm{VP}^{\dagger}$ & 0.32 & 1 & 1 & 1 & 0.32 & 1 & 1 & 1 & 1 & 1 & 1 \\
\hline $\mathrm{LPI}^{\dagger}$ & 1 & 0.32 & 1 & 1 & 1 & 1 & 1 & 1 & 1 & 0.32 & 1 \\
\hline $\mathrm{MDI}^{\dagger}$ & 1 & 1 & 1 & 1 & 0.32 & 0.32 & 1 & 1 & 1 & 0.32 & 1 \\
\hline$C^{\ddagger}$ & 1 & 1 & 1 & 1 & 1 & - & - & 1 & 1 & - & 1 \\
\hline $\mathrm{R}^{\ddagger}$ & - & 1 & - & 1 & 1 & - & - & 1 & - & 1 & 1 \\
\hline $\mathrm{RI}^{*}$ & - & 1 & - & 1 & 1 & - & - & 1 & - & 1 & 1 \\
\hline Treat * & - & 1 & 1 & - & - & - & - & - & 1 & - & - \\
\hline Diff $^{\dagger}$ & 0.11 & 0.32 & 0.32 & 1 & 0.18 & 0.16 & 0.32 & 1 & 0.32 & 1 & 0.32 \\
\hline
\end{tabular}

LPP: Labiopalatal position; MDP: Mesiodistal position; VP: Vertical position; LPI: Labiopalatal inclination; MDI: Mesiodistal inclination; C: Contact; Cl: Contacted incisor; R: Resorption; RI: Resorbed incisor; Treat: Treatment plan; Diff: Difficulty of the case; Obs: Observer; *using McNemar-Bowker test; ${ }^{\dagger}$ Using Wilcoxon matched-pairs signed-ranks test; ${ }^{*}$ Using McNemar test; It was not possible to perform the McNemar-Bowker for some nominal variables and McNemar for some dichotomous variables because the observer's responses was consistent between T1 and T2 so that the statistical software considered these variables 'constant' and no result was given

Table 7: Krippendorff's alpha coefficients for interobserver agreement in terms of 2D and CBCT-based assessments

\begin{tabular}{lll}
\hline Variable & $\begin{array}{l}2 D \text { interobserver } \\
\text { agreement }\end{array}$ & $\begin{array}{l}\text { CBCT interobserver } \\
\text { agreement }\end{array}$ \\
\hline LPP & $0.25^{\ddagger}$ & $0.87^{*}$ \\
MDP & $0.88^{*}$ & $0.95^{*}$ \\
VP & $0.6^{\ddagger}$ & $0.83^{*}$ \\
LPI & $0.73^{\dagger}$ & $0.84^{*}$ \\
MDI & $0.88^{*}$ & $0.92^{*}$ \\
C & $0.14^{\ddagger}$ & $0.58^{\ddagger}$ \\
CI & $0.22^{\ddagger}$ & $0.62^{\ddagger}$ \\
R & $0.13^{\ddagger}$ & $0.38^{\ddagger}$ \\
RI & $0.14^{\ddagger}$ & $0.46^{\ddagger}$ \\
Treat & $0.12^{\ddagger}$ & $0.12^{\ddagger}$ \\
Diff & $0.35^{\ddagger}$ & $0.24^{\ddagger}$ \\
Mean & $0.38^{\ddagger}$ & $0.68^{\dagger}$ \\
\hline
\end{tabular}

LPP: Labiopalatal position; MDP: Mesiodistal position; VP: Vertical position; LPI: Labiopalatal inclination; MDI: Mesiodistal inclination; C: Contact; Cl: Contacted incisor; R: Resorption; RI: Resorbed incisor; Treat: Treatment plan; Diff: Difficulty of the case; Employing Krippendorf's alpha coefficient: ${ }^{*} \alpha \geq 0.800$ high, ${ }^{\dagger} 0.800>\alpha \geq 0.667$ tentative, ${ }^{\ddagger} \alpha<0.667$ low. $^{30}$

from 25 to 30 years which may be considered as another factor in the observed consistency. The current results are in harmony with those of Alqerban et al. ${ }^{14}$ However, they depended on a panel of assessors including general dental practitioners and some postgraduate students, which brings into question the value of having a homogenous group of assessors with one specialty and similar training. It seems that the calibration procedure and the instructions given prior to evaluation are more important than age, specialty or experience to ensure high interobserver consistency.

A low agreement was observed among observers when evaluating the 'treatment plan' and 'case difficulty' on both CBCT and 2D imaging modalities, and this might be due to the absence of strict clinical guidelines that could have enabled the observers to arrive at consistent estimations of these two variables. The observers in the current study were given either a 3D- or a 2D-package of images but the lower jaw was not presented, i.e. the skeletal and interarch dental relationships were absent. This may have contributed to the low interobserver reliability in deciding the best treatment plan and estimating the difficulty of the case. Our reliability results regarding the treatment plan decision $(\alpha=0.12)$ are similar to those of Wriedt et al. ${ }^{34}$ The low level of agreement regarding root resorption diagnosis on CBCT may be due to the absence of a definition of a clinically significant threshold of resorption and current results are similar to those mentioned by Alqerban et al. ${ }^{14,28}$

The interobserver agreement regarding the assessment of canine proximity with the adjacent structures on CBCT was low. This may be due to the differences among the observers in the implementation of the definition of 'actual contact' according to the calibration session that they had undergone before the commencement of the main study. Any proximity with the neighboring tooth of less than half a millimeter was considered as an indication of contact. Some observers assessed the contact relationship visually, whereas others measured the distance accurately using the available ruler within the $3 \mathrm{D}$ viewing software. The same problem of low interobserver reliability while assessing contacts was also reported by Alqerban et al. ${ }^{14}$

\section{CONCLUSION}

- The intraobserver reliability was high for both the 2D- and the CBCT-based assessments.

- The interobserver agreement was remarkably higher for the CBCT-based interpretations than that of the 2D-based ones. 
- The employed 3D categorization of locating maxillary impacted canines was found to be reliable among observers on CBCT images, whereas the 2D-based assessments were not, except for the mesiodistal position and mesiodistal inclination assessments.

\section{REFERENCES}

1. Liu DG, Zhang WL, Zhang ZY, Wu YT, Ma XC. Localization of impacted maxillary canines and observation of adjacent incisor resorption with cone beam computed tomography. Oral Surg Oral Med Oral Pathol Oral Radiol Endod 2008 Jan; 105(1):91-98.

2. Walker L, Enciso R, Mah J. Three-dimensional localization of maxillary canines with cone beam computed tomography. Am J Orthod Dentofac Orthop 2005 Oct;128(4):418-423.

3. Rossini G, Cavallini C, Cassetta M, Galluccio G, Barbato E. Localization of impacted maxillary canines using cone beam computed tomography. Review of the literature. Ann Stomatol (Roma) 2012 Jan;3(1):14-18.

4. Mason C, Papadakou P, Roberts GJ. The radiographic localization of impacted maxillary canines: a comparison of methods. Eur J Orthod 2001 Feb;23(1):25-34.

5. Ericson S, Kurol J. Resorption of incisors after Ectopic Eruption of Maxillary Canines: a CT study. Angle Orthod 2000 Aug;70(6):415-423.

6. Oberoi S, Knueppel S. Three-dimensional assessment of impacted canines and root resorption using cone beam computed tomography. Oral Surg Oral Med Oral Pathol Oral Radiol 2012 Feb;113(2):260-267.

7. Naoumova J, Kjellberg H, Palm R. Cone beam computed tomography for assessment of palatal displaced canine position: a methodological study. Angle Orthod 2014 May;84 (3):459-466.

8. Ericson S, Kurol J. Radiographic examination of ectopically erupting maxillary canines. Am J Orthod Dentofac Orthop 1987 Jun;91(6):483-492.

9. Stivaros N, Mandall NA. Radiographic factors affecting the management of impacted upper permanent canines. J Orthod 2000 Jun;27(2):169-173.

10. Counihan K, Al-Awadhi EA, Butler J. Guidelines for the assessment of the impacted maxillary canine. Dent Update 2013 Nov;40(9):770-772.

11. Pitt $S$, Hamdan A, Rock P. A treatment difficulty index for unerupted maxillary canines. Eur J Orthod 2006 Apr;28(2): 141-144.

12. Kau CH, Pan P, Gallerano RL, English JD. A novel 3D classification system for canine impactions-the KPG index. Int J Med Robot 2009 Sep;5(3):291-296.

13. Haney E, Gansky SA, Lee JS, Johnson E, Maki K, Miller AJ, Huang JC. Comparative analysis of traditional radiographs and cone beam computed tomography volumetric images in the diagnosis and treatment planning of maxillary impacted canines. Am J Orthod Dentofac Orthop 2010 May;137(5): 590-597.

14. Alqerban A, Jacobs R, Fieuws S, Willems G. Comparison of two cone beam computed tomographic systems versus panoramic imaging for localization of impacted maxillary canines and detection of root resorption. Eur J Orthod 2011 Feb;33(1):93-102.
15. Dalessandri D, Migliorati M, Rubiano R, Visconti L, Contardo L, Di Lenarda R, Martin C. Reliability of a novel CBCT-based 3D classification system for maxillary canine impactions in orthodontics: the KPG index. Scientific World J 2013 Oct 9;2013:921234.

16. Al-Homsi, HK. Evaluation of the diagnostic accuracy of cone beam computed tomography and the traditional radiography in the 3D localization of maxillary impacted canines [Dissertation]. Damascus: Damascus University; 2015.

17. Hajeer MY.3D Evaluation of Upper Impacted Canines using Cone Beam Computerised Tomography (CBCT) in a Syrian Sample of Orthodontic Patients. Univ Al-Baath J Med Sci 2012;32(4):501-520.

18. Jung $\mathrm{YH}$, Liang $\mathrm{H}$, Benson BW, Flint DJ, Cho BH. The assessment of impacted maxillary canine position with panoramic radiography and cone beam CT. Dentomaxillofac Radiol 2012 Jul;41(5):355-360.

19. Lai CS, Bornstein MM, Mock L, Heuberger BM, Dietrich T, Katsaros C. Impacted maxillary canines and root resorptions of neighbouring teeth: A radiographic analysis using cone beam computed tomography. Eur J Orthod 2013 Aug;35(4): 529-538.

20. Ericson S, Kurol J. Resorption of maxillary lateral incisors caused by ectopic eruption of the canines. A clinical and radiographic analysis of predisposing factors. Am J Orthod Dentofac Orthop 1988 Dec;94(6):503-513.

21. Leonardi M, Armi P, Franchi L, Baccetti T. Two interceptive approaches to palatally displaced canines: a prospective longitudinal study. Angle Orthod 2004 Oct;74(5):581-586.

22. Alessandri Bonetti G, Zanarini M, Danesi M, Parenti SI, Gatto MR. Percentiles relative to maxillary permanent canine inclination by age: a radiologic study. Am J Orthod Dentofac Orthop 2009 Oct;136(4): 486.e1-e6.

23. Alqerban A, Willems G, Bernaerts C, Vangastel J, Politis C, Jacobs R. Orthodontic treatment planning for impacted maxillary canines using conventional records versus 3D CBCT. Eur J Orthod 2014 Dec;36(6):698-707.

24. Maverna R, Gracco A. Different diagnostic tools for the localization of impacted maxillary canines: clinical considerations. Prog Orthod 2007;8(1):28-44.

25. McSherry PF. The ectopic maxillary canine: a review. Br J Orthod 1998 Aug;25(3):209-216.

26. Motamedi MHK, Tabatabaie FA, Navi F, Shafeie HA, Fard BK, Hayati Z. Assessment of radiographic factors affecting surgical exposure and orthodontic alignment of impacted canines of the palate: A 15-year retrospective study. Oral Surg Oral Med Oral Pathol Oral Radiol Endod 2009 Jun;107(6): 772-775.

27. Jacobs SG. Radiographic localization of unerupted maxillary anterior teeth using the vertical tube shift technique: the history and application of the method with some case reports. Am J Orthod Dentofac Orthop 1999 Oct;116(4):415-423.

28. Alqerban A, Jacobs R, Souza PC, Willems G. In-vitro comparison of 2 cone beam computed tomography systems and panoramic imaging for detecting simulated canine impactioninduced external root resorption in maxillary lateral incisors. Am J Orthod Dentofac Orthop 2009 Dec;136(6):764.e1-e11.

29. Landis JR, Koch GG. The measurement of observer agreement for categorical data. Biometrics 1977 Mar;33(1):159-174.

30. Krippendorff, K. Content analysis. An introduction to its methodology. Thousand Oaks, CA: Sage; 2004. p. 413. 
31. Hering JT. The effectiveness of orthodontists and oral radiologists in the diagnosis of impacted maxillary canines [Dissertation]. Chapel Hill, North carolina: University of North Carolina; 2006.

32. Fox NA, Fletcher GA, Horner K. Localising maxillary canines using dental panoramic tomography. Br Dent J 1995 Dec 9-23; 179(11-12):416-420.
33. Armstrong C, Johnston C, Burden D, Stevenson M. Localizing ectopic maxillary canines-horizontal or vertical parallax? Eur J Orthod 2003 Dec;25(6):585-589.

34. Wriedt S, Jaklin J, Al-Nawas B, Wehrbein H. Impacted upper canines: examination and treatment proposal based on 3D versus 2D diagnosis. J Orofac Orthop 2012 Jan;73(1): 28-40. 